\title{
Models of Health workforce Planning - A Review
}

\author{
${ }^{1}$ Dr. Susanthironanki, ${ }^{2}$ Dr. Suhaskulkarni, ${ }^{3}$ Dr. B.Srikanth Reddy, ${ }^{4}$ Dr. \\ Dolardoshi. ${ }^{5}$ Dr. Padma Reddy
}

\begin{abstract}
Health workforce planning is important as the right mix of quantity and type of personnel will facilitate provision of care by the most appropriate personnel and hopefully improve the population's oral health at regional, provincial and national levels. Numerous workforce models have been developed to assist oral health planners in deciding the appropriate number and the proper mix of human resource skills. The method chosen to estimate workforce requirement reflects the political and economic choices and social values of a health system. Most of the models intend to define the supply versus requirements gap. The supply of health care is the stock of health workforce available at present or in the future to deliver health care.This research highlights the fact that there is a need for an organized national health workforce planning system to control the supply and demand of dental manpower, to ensure a uniform distribution of manpower in both urban and rural areas and to provide dental care.
\end{abstract}

Keywords: manpower, need, demand, workforce planning

\section{Introduction}

Health-care systems worldwide address the needs of the people but the shortage of health professionals is an issue that both developed and developing economies have to face ${ }^{1}$. The health workforce is defined as a group of people aiming to promote, protect and improve the health of a population ${ }^{2}$ but over time it has been subjected to globalization, provoking migration of skilled intellectual and technical labor to more highly developed countries leading to insufficient personnel to meet local health-care needs $\mathrm{s}^{2,3}$.

Health workforce planning is a complex and systematic process which aims to determine the appropriate number and composition of health teams required to improve the level of health in the population ${ }^{6}$. Careful planning in the production and deployment of health workforce is important to ensure that their uses are optimized. A number of health workforce models have been developed to assist planners in estimating human resources requirements. The method chosen by health planners reflect their political, economic and social values of a health system.In the early 1960s, the aim of workforce planning was to achieve and sustain "the right number of people, in the right place, with the right skills, at the right time". More recently, driven by financial limitations and demands for efficient use of resources, the additional importance of finding workers "with the right attitudes, doing the right work, at the right cost, with the right productivity" was emphasized".

A practical approach to workforce planning involves the following steps: i) the establishment of measurable goals for oral health services based on situation analysis, taking into consideration of available workforce, facilities and funds; ii) the calculation and distribution of the workforce needed to achieve the goals; iii) the assessment of the health services goals that can be achieved with the current available workforce and the training programme that are in operation or needs to be developed; iv) the modification of goals if there is no combination of workforce that can satisfy the initial goals; v) recalculating the workforce needed for the new goals; vi) the establishment of the quantitative and qualitative goals for workforce production ${ }^{10,11}$. These steps need to be repeated until the number and types of workforce required to deliver the oral health goals is achieved. The target should not be about producing the highest proportion of health professionals, the aim should instead set on having the quantum suitable with the population needs, demands and the country's health budget ${ }^{8}$.

Numerous workforce models have been developed to assist oral health planners in deciding the appropriate number and the proper mix of human resource skills. The method chosen to estimate workforce requirement reflects the political and economic choices and social values of a health system ${ }^{7}$. Most of the models intend to define the supply versus requirements" gap $^{12}$.

\begin{tabular}{|cl|}
\hline \multicolumn{2}{|c|}{ Models of Health Workforce Planning: } \\
\hline 1. & Health Needs Model \\
\hline 2. & Health Demands Model/ Utilization Technique \\
\hline 3. & Service Targets Method \\
\hline 4. & The Manpower to Population Ratio method \\
\hline 5. & The Econometric Model \\
\hline
\end{tabular}




\section{Health Needs Model}

The Health Needs Model uses the current disease levels of the population to calculate the workforce requirements ${ }^{7,8,13}$. Professional judgment or normative need is used to estimate the most appropriate services and technologies needed for a specific type of health needs. The number, type, frequency and quality of services to be provided to the section of the population that suffers from diseases are quantified and these are converted into the amount of time required by health professionals to perform the services. The current quantity of health providers needed is calculated using estimates of health professional's annual working hours and the population's health status or treatment need ${ }^{7}$. A forecast of future health workforce requirements can also be made based on the trends in the population's health needs and the demographic distribution of health professionals $^{13}$. The health needs approach is explained using the following formula ${ }^{6,12}$ :

$\mathrm{Mpt}=\mathrm{P} * \mathrm{C} * \mathrm{~V} * \mathrm{~T}$

W

\section{Where:}

$\mathrm{Mpt}=$ workforce required in year $\mathrm{t}$;

$\mathrm{P}=$ the population that needs a given type of care for a specific health problem in year $\mathrm{t}$ (current or projected)

$\mathrm{C}=$ the average number of conditions' per person per year

$\mathrm{V}=$ the average number of a given kind of service per condition per year, based on need

$\mathrm{T}=$ average time required per service

$\mathrm{W}=$ average workload of the individual practitioner - total amount of service time provided by the average practitioner per year for a given service.

The health needs method can be perceived as rational by both health professionals and members of the public because it is consistent with social and professional ethics which warranted that health services be provided to all those in need regardless of their social and economic circumstances. The health needs method was considered suitable for use in a country with a sound planning capacity, an active government policy toward health, a dominant public sector, and a relatively high public awareness of health issues ${ }^{7}$.

\section{Strengths ${ }^{8,12}$ :}

1. Logical and easy to understand.

2. Consistent with professional ethics.

3. Has the potential of addressing the health needs of the population using a mix of human resources for health.

4. Useful in a health programme where the health problems and the health services needed are clearly demarcated.

Limitations $^{14,15,16}$ :

1. Requires a high level of skills and knowledge of the health care workers

2. Ignores the question of efficiency in allocation of resources among other sectors eg school teachers, primary health workers

3. Ignore the perceived needs of the population and other impacts of healthy population

4. Ignores the reality of economic demand

5. Difficulty of converting the dental health status measurement into treatment needs

6. Does not take into account evidence-based dentistry and use of outdated approaches by health professionals

7. Is likely to project unattainable service and staff targets.

\section{Health Demands Model / Utilization Technique:}

In this method, workforce requirements are projected based on current and estimated future utilization rates. Indices of demand are constructed using utilization rates by age, sex, occupation and race; and future demand is derived from the expected changes in the size of these population groups and the proportionate change in services that this might imply in the future ${ }^{6,13}$. Demand and utilization are two terms that have been used interchangeably. Demand is defined by the seeking behaviour for health care by patients, resulting directly from the perceived or subjective need for treatment ${ }^{17,18}$ while the term utilization refers to the amount of dental care consumed or purchased as a result of compromised decisions between the patients and providers ${ }^{19}$. The workforce requirement is projected based on the data of dental utilizations obtained from health providers, the average dental visits made by the patients and the expected population growth ${ }^{6}$. Proxies for demand/utilization data have been used such as practitioner's productivity or professional opinion surveys. DeFriese and Barker $(1982)^{12}$ or other influences of demand such as data on dental insurance or socioeconomic status ${ }^{20}$. 
The demand-based method is based on several assumptions. Demands or the productivity of the health care providers observed in the past or in the base year are assumed to remain constant over time despite any possible changes of the populations ${ }^{\text {ee }}$ demographic profile and evolution of tasks for health workers ${ }^{8,11,12}$. The supply of dentists is assumed to rise according to market demands and increases in patient visits will require proportionate increases in dental workforce requirements. It is also presumed that there is less or no variability among dentists in terms of their patient volume and auxiliary utilization.

\section{Strengths ${ }^{6,20}$ :}

1. provides a comprehensive view of the dynamics of health services utilization

2. avoid the risk of setting excessively expensive or unrealistic objectives

3. captures more of the reality of the dental marketplace

\section{Limitations ${ }^{11,20,21,22}$ :}

1. Relies heavily on utilization rates and assumes that increases in demand should create increased supply.

2. Fails to understand that there are some populations who are in need but could not demand for it.

3. It violates severe fundamental assumptions of a perfectly competitive market

4. Does not take into account financial or economy factors.

5. Produces a status quo projection, since future population segments are assumed to have similar utilization rates as base year segment

Service Target Method: The Service Target Method involves the setting of targets by health authorities for the production and delivery of specified health services at various levels of care, considering the current level of technology, the demand of the population for certain services and the various services already performed by health workers. Compared to the need and demand-based method, this method uses other criteria to develop targets, which would consequently create demand or provision of health workforce. These other criteria include factors such as the public demand for services, political views, costs, efficiency for service delivery, likely effects, segment of the population benefitted, access and administrative feasibility ${ }^{6,7,8}$. When the number of services has been identified, the workforce required to render the services is calculated.This method was used by Adams and Woods (1990) ${ }^{23}$ when estimating physicianse requirements for Canada. They assessed the current levels and future targets of service adjusted by experts ${ }^{\text {ee }}$ opinion on the norms provision of care.

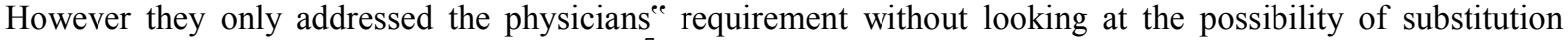
among health workers. Dreesch et al $(2005)^{7}$ addressed this limitation by combining both the service target approach and functional job analysis to estimate the human resources needed to achieve the Millennium Development Goals (MDGs). The potential for sharing skills among various objectives/health programmes and combining and substituting various skills were identified in that study.

\section{Strengths ${ }^{7,8,24}$}

1. Breaks down the activity and components of health services which facilitates estimation of demand.

2. easy to put into practice.

3. Allows assessment of interaction between variables.

4. Places the importance of productivity.

5. Simplifies cost estimates.

6. Active approach towards improving the health services.

\section{Limitations $^{7}$ :}

1. It allows the planner discretion in departing from extrapolations of past experience.

2. Errors of judgment could be made on productivity rate and capacity to deliver.

\section{The Manpower to Population Ratio method:}

The Manpower to Population Ratio is the simplest workforce method to apply and to understand compared to other approaches as it is a count of health care personnel for a given population. The desirable ratios are established on the basis of current situations, international comparisons, recommended standards, ratios observed in a favored area of the country and extrapolation of past trends ${ }^{6,7}$. However, the ratio used is arbitrary and not universally defined and usually depends on disease levels, workforce adequacy and oral health goals ${ }^{10}$. For example, at one point it was suggested that the acceptable ratio is one dentist to every 2000 people $^{25}$, and then a decade later the recommended ratio changed to one dentist to every 5000 people ${ }^{26}$. WHO $(1980 \mathrm{~b})^{10}$ outlined a working basis for oral health services planning based on the following workforce ratio:

i. Ratio of 1:20,000 and lower requires planner to focus more on the assessment of existing and projected resources over the next 10 years. 
ii. Ratio of between 1:20,000 to 1:50,000 encourage a more ambitious health care planning.

iii. Ratio of 1:5000 and higher requires a plan for a more comprehensive coverage of the populations oral health needs.

This method is based on several assumptions, most of which are not justified and cannot be easily defended. The model assumes that there will be a constant need and demand of health professionals ${ }^{8,13,27}$, regardless of changes in the populations demographic profiles, changes of health pattern, political and economic situations and research advances. It also assumes that health professionalse productivity would remain the same and that there will be no evolution of tasks for both the professionals and other supporting health workers and no advances in technology would be further created ${ }^{7,20,28}$. The supplies of health workforce and health facilities are assumed to be independent of wages and demands for health services are independent of prices and ability to $\mathrm{pay}^{28}$. The straight forward calculations of the number of health workforce to the number of population, without disaggregating them into different geographical areas, would presumably indicate that there is reasonable geographical distribution of health workforce in both areas. Some modifications of the manpower-population approach have been proposed. Thailand modified this method by including other measurements such as the specific characteristics of the Thai health care system and the future economic scenarios ${ }^{29,30}$ estimated the number of dentist needed in the United States by adding measures of total dental output and gross billings of dental practice in the ratio method. Others have included adjustments for factors such as the age of the health professionals, the impact of water fluoridation and the increased productivity due to average auxiliary utilization $^{31}$.

\section{Strengths $\mathrm{s}^{7,20,21,28}$}

1. Cheap, quick, easy to apply and to understand/interpret, and requires little information

2. Allows comparison be made between different continents.

Limitation $^{8,20,21}$ :

1. Does not consider how demand and supply forces interact

2. Assumes that the demand of each people is the same

3. Fails to recognize and address the different levels of disease in different age cohorts

4. Ignores the various categories of oral health auxiliaries

5. Implies that wages, prices and other costs need not be considered in the calculation.

The Econometric Model: The Econometric Model is sometimes described as a simple equation of supply and demands which requires few variables, but other times it is defined as a complex equation that could involve numerous variables ${ }^{31}$. Data required for projection would depend on the scope and complexity of that particular model. This model uses the interaction between supply and demand, but emphasizes the price of health care (to the patient) and income (to the providers) as the primary factors. The model divides the health sector into a demand sector, which is concerned with the decisions of the general population to seek care; and a supply sector which is concerned with the decisions of providers to supply care ${ }^{32}$. The interaction between these two will determine how much care is provided, to whom, and at what prices. The actual demand will depend upon the prices people are willing to pay for the services which includes the price of dental care, annual per capita income of the population, availability of health insurance and waiting time, both in securing an appointment and in being kept waiting in the health care agency ${ }^{32,33}$. Health care providers' willingness to offer services (supply) will depend upon the price received the value providers place on their own time, wages paid to other supporting health personnel and the state of existing technology. Given all the factors involved in determining supply and demand, it is the price that ultimately adjusts so that quantity supplied equals quantity demanded ${ }^{32}$.

The econometric model looks at many major economic variables that would influence demand and supply and uses possible scenarios to gauge possible consequences. This method was used in dental workforce projection in Wisconsin, United States ${ }^{30}$. Economic factors such as dentist location, average income, dental insurance and other practice costs were included in the modeling. The findings suggested a misdistribution of dentists in which concentration was highest in the largest counties ${ }^{30}$. This model assumes that the supply of workforce determines the demand, rather than vice versa ${ }^{12}$ and that there is a constant interdependency between supply and demand. Certain variables are presumed to be the critical components in the health financial system and the relationship of those variables to the production of services is assumed to behave in accordance with general economic theory ${ }^{31}$. 
Strengths ${ }^{24,31,33}$ :

1. Scientific and objective approach.

2. Solid theoretical base, cost-conscious and can be subjected to testing and analysis.

3. Could gain review from health economists.

Limitations ${ }^{20,31,33}$ :

1. Data required are either nonexistent or inadequate

2. Health economic system may not behave in a traditional manner as presumed by the economists

3. Ignores the role of other supporting health workers

4. Does not sufficiently consider population health needs, budget pressures, political/ socio/ economic factors, the influence of the changing health system and the impact of outcomes.

The WHO/FDIJWG6 Model (Need Based, Demand Weighted Method):In 1988, a Joint Working Group of the WHO and the FDI developed a spreadsheet computer programme (WHO/FDI JWG6) for prediction of dental workforce requirements. The proposed model takes into account various types of data: basic data for calculating oral care needs, modifying factors which influence decision-making and decisions on options and strategies available for plan implementation (Figure 1) $34,35,36$. The final outcome of the computer programme is expressed as an operator-to-population ratio specific for that population.

\section{This Computer Programme Provides Two Sets Of Calculated Results:}

a. The quantity of services required dealing with the needs of current and projected population and the full time equivalent (FTE) personnel needed to provide them.

b. The quantity of services which could actually be provided given the level of demand.

The computer programme also requires that dental needs are divided into seven distinct groups for each age cohort (0-14 years, 15-29 years, 30-64 years, and 65-79 years). These are special group care (handicapped or geriatric), surgical group care (impaction and trauma), orthodontic care, restorative care, periodontal care, preventive care and prosthetic care ${ }^{34,36}$. The WHO/FDI model has been used to estimate dental workforce requirements in France ${ }^{35}$. The model's prediction of the dentist to population ratio was similar to the current situation in France. However, that does not mean that the ratio was appropriate for that population. When using this model for projecting workforce needs for dentists in Lebanon, the model suggested that the projected supply of dentist will exceed the required number of dentists ${ }^{37}$.

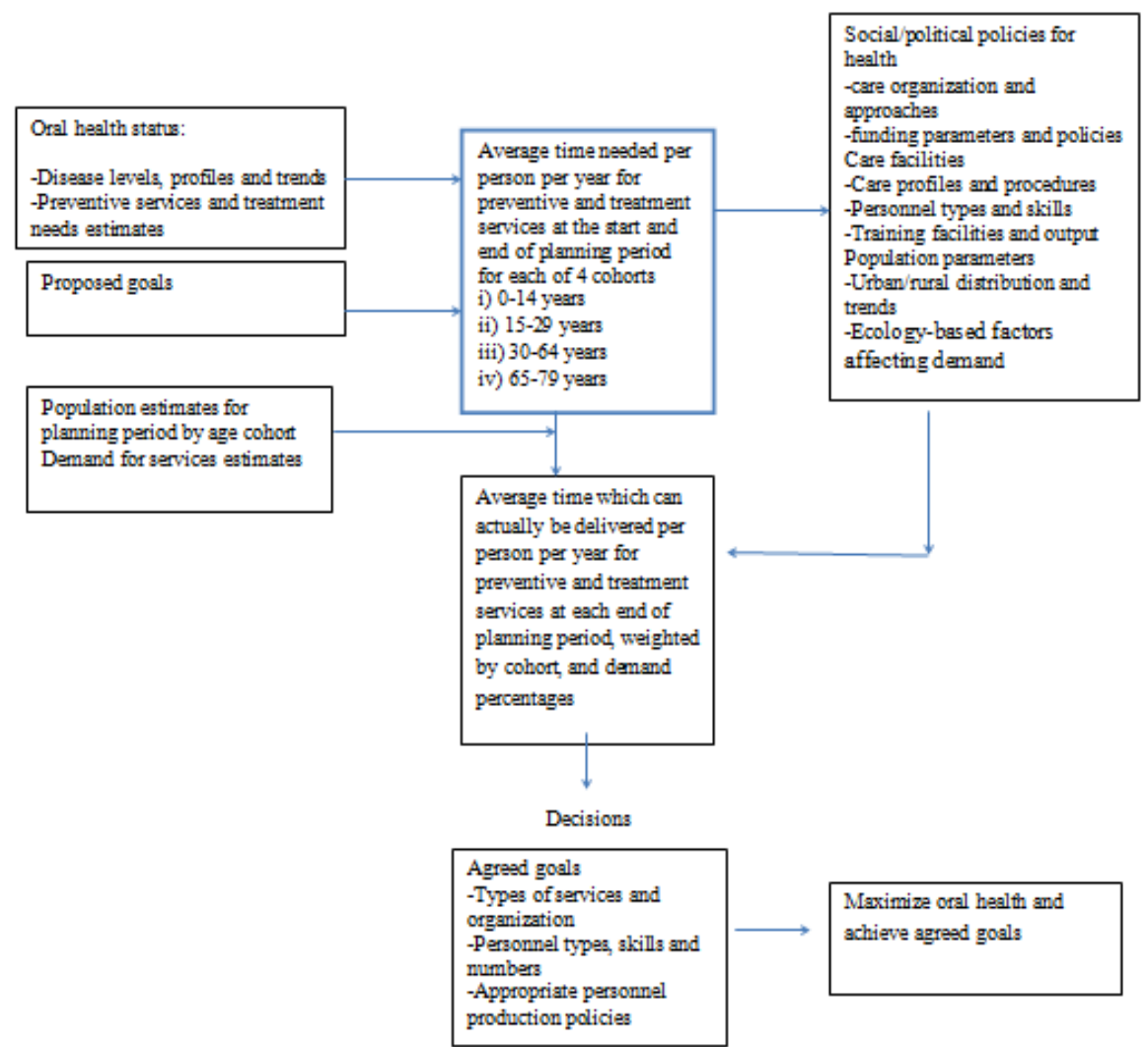

Figure 1: Planning Flow Chart For WHO/FDI JWG6 Programme (WHO 1989) 


\section{Strengths ${ }^{38}$ :}

1. Enables the user to forecast requirements, by age cohort and by type of care, while at the same time including socio-economic variables

2. Flexible and adaptable.

Limitations $^{36,39}$ :

1. Neglects cohort and period effects.

2. Neglects aspects of demand and provide overly simplistic answers to complex questions.

3. Ignores the role of other supporting health workers.

4. Ignores socio-economic factors that could modify the behavior and the practice of dentists.

\section{System Dynamic Model:}

System Dynamic Model is a computer simulation programme that illustrates processes of accumulation and feedback and is used to find effective policies using various scenarios that can be tested in a systematic way that answers both what if ${ }^{\text {ee }}$ and ,why ${ }^{\text {ee }}$. It was developed in the mid-1950s by computer pioneer, Jay W. Forrester. A key emphasis within the model is placed on the presence of feedback loops, characterized as loop of causes and effects. The details of causal factors that are responsible for a particular problem or affect the performance of a system needs to be laid out first. Then these causal factors are represented in diagrams that make the relationships among them explicit. It was suggested that the enumeration and diagramming steps should be carried out with active participation of decision makers. ${ }^{40,41}$

The System Dynamic model has been applied in dentistry by Hirsch and Killingsworth $(1975)^{42}$ and Steering Committee on Future Health Scenarios $(1994)^{43}$. It was used in the Netherlands to simulate a model of supply and demand of the dental health care system. The model consisted of five sub-models concerning the population, the dental attendance behaviour, the pathology model which assessed the dynamic of caries and periodontal disease, the supply model which gave figures for the work potential of dentists and dental hygienists, and the treatment model ${ }^{44}$. Five different oral health scenarios were developed on the basis of the developments and expectations regarding dental health care and were tested on the simulation model ${ }^{43}$. The result showed that the model was able to replicate fairly well the behaviour of the Dutch dental health care system as observed for the period $1970-1984^{45}$.

System dynamics shows potential of modeling multiple interacting diseases and risks and the relations between delivery system and diseased population ${ }^{41}$. It is useful in a data poor environment as model can be developed using important variables regardless the quality of the data. Consequently it will assist decisionmakers to identify data that should be collected in the future ${ }^{40}$. The major strength of this model is that it requires the involvement of decision-makers in the process. This would create a better understanding of the health scenarios being modeled and the greater commitment on the decision-maker's part to use the results subsequently. However decision-makers could be reluctant to take part in the disciplined and slow process of computer modeling. It will also not excite those who do not trust findings based on intuition ${ }^{40}$. Besides that, the requirement of multiple data might lead to overly complex models that are difficult to work with or to understand.

\section{Strengths ${ }^{40,41}$ :}

1. Requires involvement of policy maker which will results use of product for policymaking

2. Useful in data-poor environments

3. The outcome is applicable at strategic level, concerning policies and new programme.

Limitations $^{40}$ :

1. Decision maker might not want to be involved in the disciplined and slow process

2. Decision makers might be unfamiliar with the technical aspects

3. Too much data are needed and might lead to overly complex models that are difficult to work with.

4. Unpredictability based on incomplete data and the unpredictability based on non-linear feedback loop.

\section{Overall appraisal of the health workforce planning models}

The different types of workforce planning models can be utilized by decision-makers in deciding the quantity and quality of health workers appropriate at the level of diseases and services available and affordable within the specified health budget. It is important to weigh the strengths and limitations of each model before choosing the right approach as different type of model chosen will generate different outcomes. Most of those methods discussed earlier, especially the Manpower to Population Ratio approach, are profession-specific and have largely failed to recognize the potential of substitution between health professions ${ }^{7}$. Nevertheless it is the most commonly used method to estimate dental workforce. 


\section{Reference}

[1]. Clark PF, Stewart JB, Clark DA. Migration and recruitment of healthcare professionals: causes, consequences and policy responses. Policy Brief. Hamburg Institute of International Economics (HWWI), The German Federal Agency for Civic Education (bpb) and Network Migration in Europe. No. 7, August, 2007. Available from: http://www.hwwi.org/uploads/tx_wilpubdb/PB07_Health.pdf. Accessed 8 May 2013.

[2]. Dal Poz M, Kinfu Y, Drager S et al. Counting health workers: definitions, data, methods and global results. Background paper prepared for working together for health: the World Health Report 2006. Available from: http://www.who.int/hrh/documents/counting_health_workers.pdf. Accessed 8 May 2013.

[3]. Gallagher JE, Wilson NH. The future dental workforce? Br Dent J 2009 206: 195-199. Available at: http://www.nature. com/bdj/journal/v206/n4/full/sj.bdj.2009.114.html. Accessed 20 February 2013.

[4]. Guide to workforce planning at the Department of Energy. Human Capital Management Strategic Planning and Vision, September 2005. Available at: http://humancapital.doe.gov/ resources/GuideWorkforcePlan.pdf. Accessed 14 February 2013.

[5]. Workforce Planning Instruction Manual. U.S. Department of the Interior Office of Personnel Policy, August 2001.

[6]. Hornby P, Ray DK, Shipp PJ, Hall TL. Guidelines for health manpower planning: Geneva: World Health Organization 1980

[7]. Dreesch, N, Dolea, C, Dal Poz, M R., Goubarev, A, Adams, O, Aregawi, M. et al. An approach to estimating human resource requirements to achieve the Millennium Development Goals. Health Policy Plann 2005; 20(5): 267-76.

[8]. Hall T L and Mejia A. Health manpower planning: Principles, methods, issues. Geneva: World Health Organization 1978: 279

[9]. HornbyP. Exploring the use of the World Health Organization human resources for health projection model. Available at: http://www.capacityproject .org/workforce planning-workshop/presentations/WHO 2007.hornby.ppt (Accessed on 12 September 2008)

[10]. WHO. Planning Oral Health Services: Geneva: World Health Organization 1980b.

[11]. McQuide P, Stevens, J, Settle D. An overview of human resources for health (HRH) projection models. The Capacity Project: United States Agency for International Development(2008).) Available at: http://www.capacityplus.org/hris/hris-toolkit/tools/pdf/ techbrief_12.pdf (Accessed 14 February 2012).

[12]. DeFriese, GH and Barker BD. The status of dental manpower research. J Dent Educ1983; 47(11):728-37.

[13]. Roberfroid, D, Leonard, C, Stordeurs, S. Physician supply forecast: Better than peering in a crystal ball? Hum Resour Health 2009;13(7): 10 .

[14]. Schonfeld, WH. Estimating dental treatment needs from epidemiological data. J Public Health Dent 1981;41(1): 25-32.

[15]. Nuttall, NM and Elderton, RJ 1983. The nature of restorative dental treatment decisions. Br Dent J 1983;154(11): 363-5.

[16]. Naegele ER, Cunha-Cruz J, Nadanovsky P. Disparity between dental needs and dental treatment provided. J Dent Res 2010; 89(9), 975-9.

[17]. Spencer AJ. The estimation of need for dental care. J Publ Health Dent1980;40(4): 311-27.

[18]. Davis P. Converting the need for care into demand for services. Int Dent J1982; 32(3):271-80.

[19]. Grytten, J. Supplier inducement--its relative effect on demand and utilization. Community Dent Oral Epidemiol 1992;20(1): 6-9.

[20]. Odrich, J. Dental manpower planning: can we ever get it right? J Public Health Pol 1985;6(4): 539-52.

[21]. Goodman HS and Weyant RJ. Dental health personnel planning: a review of the literature. J Public Health Dent 1990;50(1): 48-63.

[22]. Bronklehurst, PR. and Tickle M. Planning a dental workforce for the future for the National Health Service in the United Kingdom: What factors should be accounted for? Health Educ J 2011;70(2): 3-14.

[23]. Adams O and Woods A. Physician resource planning. The 'adjusted service target approach. A suggested pilot project. Prepared for the Royal College of Physicians and Surgeons of Canada. Ottawa 1990: Curry Adams \& Associates, Inc.

[24]. Wibulpolprasert, S. Human resources for health development in the context of health sector reform. Background paper for the EDI/WB course on Health Sector Reform and Sustainable Financing, Washington DC. 17-21 November 1997. Washington DC: World Bank.

[25]. Rosenbaum J, Speicher, KA, Tannenbaum, KA, and Mumma, RD. A method for assessing dental manpower need is tested in a low income area of Philadelphia. Public Health Rep 1975; 90(3): 257-61.

[26]. Holler I, and Machans, N. Concept of dental health for all in the year 2000. World Health Organization. As cited in 'Baseline projection of requirements for dental health manpower in Thailand (1995-2015)'. Punyasingh, K., Udompanich, S., Lexomboon, D. (1997), HRDJ 1:24-34

[27]. Sheiham, A. Planning for manpower requirements in dental public health. In. G. L. Slack and B. A. Burt, (eds.). Dental public health: An introduction to community dental health. Bristol: John Wright and sons 1981;Chapter 8: 160-199.

[28]. Yett, DE, Drabek, L, Intriligator MD, and Kimbell LJ. Health manpower planning: an econometric approach. Health Serv Res 1972; 7(2):134-47.

[29]. Sirikanokvilai N. Modified population-to-physician ratio calculation method to project future physician requirement in Thailand. HDRJ 1998;2(3): 197-209.

[30]. Beazoglou, T, Heffley D, Brown LJ, Bailit, H. The importance of productivity in estimating need for dentists. J Am Dent Assoc 2002b;133(10): 1399-404.

[31]. Born DO. Issues in forecasting graduate dental education manpower supply and requirements. J Dent Educ 1981;45(6): 362-73.

[32]. Feldstein PJ and Roehrig, CS. A national econometric forecasting model of the dental sector. Health Serv Res 1980; 15(4): 415-32.

[33]. O Brien-Pallas L, Baumann A, Donner G, Murphy GT, Lochhaas-Gerlach, J, Luba, M. Forecasting models for human resources in health care. J AdvNurs 2011;33(1): 120-9.

[34]. WHO / FDI. Health through oral health: Guidelines for planning and monitoring for oral health care. Quintessence Publishing Company Limited 1989: London.

[35]. Bourgeois D, Leclercq MH, Barmes, DE, Dieudonne, B. The application of the theoretical model WHO/FDI planning system to an industrialised country: France. Int Dent J 1993;43(1): 50-8.

[36]. Morgan MV, Wright, FA, Lawrence AJ, Laslett, AM. Workforce predictions: a situational analysis and critique of the World Health Organisation model. Int Dent J 1994; 44(1): 27-32.

[37]. Doughan, B, Kassak, K, Bourgeois D. Planning dental manpower in Lebanon: scenarios for the year 2015. East Mediterr Health J 2005;11 (5-6): 943-51.

[38]. Vetter NJ. Needs, supply and demand for health care by elderly people in the NHS. Rev ClinGerontol 2002;12(4): 375-80.

[39]. Bronkhorst, EM, Truin, GJ, Batchelor P, Sheiham, A. Health through oral health; guidelines for planning and monitoring for oral health care: a critical comment on the WHO model. J Public Health Dent 1991;51(4): 223-7.

[40]. Hirsch GB. System Dynamics Modelling in Health Care. Simuletter1977;38-42.

[41]. Homer JB, and Hirsch, GB. System dynamics modeling for public health: background and opportunities. Am J Public Health 2006;96(3): 452-8 
[42]. Hirsch GB, and Killingsworth, WR. A new framework for projecting dental manpower requirements. Inquiry 1975;12(2): 126-42.

[43]. Steering Committee on Future Health Scenario. Future scenarios on dental health care 1994. Kluwer Academic Publishers: The Netherlands.

[44]. Bronkhorst EM. Modelling the Dutch Dental Health Care System: a comprehensive system dynamic approach. Thesis KatholiekeUniversiteit Nijmegen 1995

[45]. Bronkhorst, EM, Niersma, T, Truin, GJ. Using complex System Dynamic models: an example concerning the Dutch dental health care system. Proceedings of the 1990 System Dynamic Conference. International System Dynamics Society: System Dynamics 1990, 155-163. 